\title{
THE
}

$12-29-2020$

\section{Carbon Nanotube-Liposome Complexes in Hydrogels for Controlled Drug Delivery via Near-Infrared Laser Stimulation}

\author{
S. Zahra M. Madani \\ Mohammad Moein Safaee \\ Mitchell Gravely \\ Carolynn Silva \\ Stephen Kennedy
}

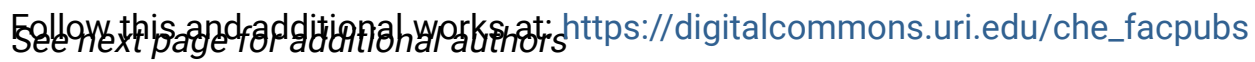

Part of the Chemical Engineering Commons

The University of Rhode Island Faculty have made this article openly available. Please let us know how Open Access to this research benefits you.

This is a pre-publication author manuscript of the final, published article.

Terms of Use

This article is made available under the terms and conditions applicable towards Open Access Policy Articles, as set forth in our Terms of Use.

\section{Citation/Publisher Attribution}

Madani, S. Zahra M.; Safaee, Mohammad Moein; Gravely, Mitchell; Silva, Carolynn; Kennedy, Stephen; Bothun, Geoffrey D.; et al. (2020): Carbon Nanotube-Liposome Complexes in Hydrogels for Controlled Drug Delivery via Near-Infrared Laser Stimulation. ACS Publications. Collection. https://doi.org/10.1021/ acsanm.0c02700 


\section{Authors}

S. Zahra M. Madani, Mohammad Moein Safaee, Mitchell Gravely, Carolynn Silva, Stephen Kennedy, Geoffrey D. Bothun, and Daniel E. Roxbury

This article is available at DigitalCommons@URI: https://digitalcommons.uri.edu/che_facpubs/53 


\section{Carbon Nanotube-Liposome Complexes in Hydrogels for Controlled Drug Delivery via Near-Infrared Laser Stimulation}

Authors: S. Zahra M. Madani $\zeta$, Mohammad Moein Safaee $\zeta$, Mitchell Gravely ${ }^{\zeta}$, Carolynn Silva ${ }^{\zeta}$, Stephen Kennedy $\zeta, \xi$, Geoffrey D. Bothun $\zeta$, Daniel Roxbury ${ }^{*}$

$\zeta$ Department of Chemical Engineering, University of Rhode Island, 2 East Alumni Avenue, Kingston, RI, US

$\xi$ Department of Electrical, Computer, and Biomedical Engineering, University of Rhode Island,

2 East Alumni Avenue, Kingston, RI, US

*corresponding author

contact email: roxbury@uri.edu

\section{Abstract}

Externally controllable drug delivery systems are crucial for a variety of drug delivery applications where the dosage and timing of drug delivery needs to be adjusted based on disease diagnosis and progression. Here, we have developed an externally controllable drug delivery platform by combining three extensively used platforms: hydrogels, liposomes, and single-walled carbon nanotubes (SWCNTs). We have developed carbon nanotube-liposome complexes (CLCs) and incorporated these structures into a 3D alginate hydrogel for use as an optically controlled drug delivery system. The CLC structures were characterized using a variety of imaging and spectroscopic techniques and an optimal SWCNT/lipid ratio was selected. The optimal CLCs were loaded with a model drug (FITC-Dex), incorporated into a hydrogel, and their release profile was studied. It was shown that release of the drug cargo can be triggered using an NIR laser stimulation tuned to the optical resonance of a particular SWCNT species. It is further shown that the amount of released cargo can be tuned by varying NIR stimulation time. 
This system demonstrates the externally controlled delivery of drug cargo and can be used for different applications including cancer chemotherapy delivery.

Keywords biomaterials, nanotechnology, stimulated drug delivery, single-walled carbon nanotubes, liposomes, hydrogels, self-assembly, near-infrared laser stimulation

\section{Introduction}

Externally controllable drug delivery systems are crucial for a variety of applications including tissue engineering and cancer chemotherapy. Cancer is the $2^{\text {nd }}$ leading cause of death in the United States and affects $40 \%$ of Americans during the course of their lifetimes. It is estimated that 4,950 new invasive cases will be diagnosed each day in the United States in 2020. ${ }^{1}$ Although many chemotherapeutic drugs have been developed for cancer, severe systematic toxicity of these drugs has limited their clinical usage. More specifically, the most efficient systems can provide drug accumulation at tumor sites with less than $1 \%$ efficiency, leaving $99 \%$ of the administered drug to adversely affect healthy tissues. ${ }^{2}$ Delivery systems are therefore developed to increase the localized dose and effectiveness of the chemotherapeutic drugs at the target sites. ${ }^{3-8}$ One of the most challenging factors in developing these systems is designing a versatile system that can be loaded with a variety of payloads rather than individually designed systems for a specific payload. Traditionally, delivery systems for specific drugs were developed based on modifications of the drug formulation or a chemical bonding of the drug to the drug carrier. While these systems have shown promise for some applications, extensive research is needed for the design of one drug delivery system applicable for one unique drug making this design step a bottleneck in the process. There are a few different design approaches that circumvent this issue by providing a platform for drug delivery. 
Hydrogels have been extensively studied and used for localized drug delivery due to their biocompatibility, modifiable properties, and high drug loading capacity. ${ }^{9-12}$ The hydrogel drug delivery systems often utilize degradation rate or other physical/chemical parameters of the hydrogel scaffold as a tool to achieve a sustained and controlled release rate. However, many cancer conditions require more complex controlled release profiles (i.e. on-demand \& real time control over release). ${ }^{4,13,14}$ Furthermore, conventional hydrogel systems can only be used to deliver hydrophilic drugs, leaving out a major group of drugs which are hydrophobic.

Stimuli responsive drug delivery systems are a class of materials developed to provide real-time control over drug release. These stimuli can be biological in nature, such as $\mathrm{pH}$, temperature, and reactive oxygen species (ROS), or can be external, such as magnetic field, ultrasound, electrical field, or light. ${ }^{11,15-21}$ To develop an external stimuli responsive system, a stimuli responsive moiety is often combined with a drug carrier moiety. Therefore, when a stimulus is applied, the responsive moiety triggers a physical or chemical change in the carrier moiety that leads to the drug release. Self-assembled liposomes offer many adjustable parameters for developing controlled drug delivery systems. ${ }^{22}$ Liposomes are often used as the drug carrier moiety as they can encapsulate both hydrophilic and hydrophobic drugs. ${ }^{23,} 24$ There are many liposomal formulations that are currently FDA-approved or are in clinical trials. ${ }^{25}$ One of the most important limitations of liposomal drug delivery is their fast clearance and low retention. To address this 
limitation, liposome/hydrogel systems are developed. These systems can achieve longterm drug delivery while utilizing unique properties of both liposomes and hydrogels. ${ }^{26,27}$ Single-walled carbon nanotubes (SWCNTs) are composed of a single graphitic layer rolled up into a one-dimensional nanocylinder. ${ }^{28,}{ }^{29}$ The existence of an electronic bandgap energy in semiconducting SWCNTs results in a variety of unique near-infrared (NIR) optical and electronic properties making them ideal candidates for various disparate fields including photothermal therapy, ${ }^{30,} 31$ bioimaging, ${ }^{32,}, 33$ biosensing ${ }^{34,}{ }^{35}$ and drug delivery. ${ }^{36-39}$ Their bandgap energies and chiral identities vary based on the roll-up direction of the graphitic layer, resulting in various species (chiralities) that differentially absorb photons with energies matching the band gap of the $E_{11}$ optical transition. These wavelengths are in the biological tissue-transparency range, including NIR-I (750-1000 $\mathrm{nm})$ and NIR-II windows $(1000-1700 \mathrm{~nm})^{28}$, which enables NIR-stimulated heating of implanted SWCNTs. Various amphiphilic polymers such as short single stranded DNA (ssDNA) ${ }^{40-42}$ and Phospholipid-Polyethylene glycol (PL-PEG) ${ }^{43}$ have been shown to effectively wrap around the SWCNTs through noncovalent m-stacking of their hydrophobic sections on the SWCNT sidewalls, resulting in enhanced biocompatibility and long-term colloidal stability. Solubilized single- or multi-walled carbon nanotubes (referred here as CNTs) have shown promise in a variety of biological applications. In most drug delivery systems, three main methods are used to induce interactions between the active compound (drug) and CNTs. The first method is to use a CNT mesh or bundle and entrap the active compounds within the meshes. The second approach involves functional attachment of the compound to exterior CNT walls and the last approach is using CNT channels as nano-catheters. ${ }^{44}$ As CNTs are stimuli-responsive and in 
particular respond to NIR laser, they can also be used as a stimuli responsive moiety in developing a drug delivery system. Here, liposomes are employed as triggerable drug carriers to prevent passive release of the cargo. This is critical as liposomes offer unique features as drug carriers such as compatibility with both hydrophilic and hydrophobic drugs, biocompatibility, and tunability.

Herein, we have developed an external stimuli responsive drug release system based on DNA-wrapped SWCNTs (DNA-SWCNTs) self-assembled onto model drug (FITC-Dex)containing liposomes (lip). We embedded the carbon nanotube-liposome complexes (CLCs) into a 3D hydrogel matrix to fabricate an implantable, NIR-responsive, localized drug release device (Schematic 1). Cationic liposomes were self-assembled with negatively charged DNA-SWCNTs to form CLCs at varying SWCNT/lipid ratios. The CLCs were characterized using dynamic light scattering (DLS), and transmission electron microscopy (TEM). The structures with optimal conditions were encapsulated into alginate hydrogels for enhanced stability and retention. The controlled localized drug release was accomplished by selectively heating the $(9,4)$-SWCNT chirality using an NIR laser at $1122 \mathrm{~nm}$, which increased the permeability of the liposomal bilayer and led to the stimulated release of CLCs' cargo. 
A

nano-scale components of

the system

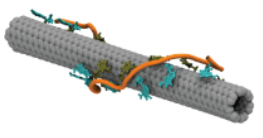

anionic DNA-SWCNT

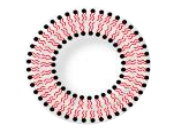

cationic liposomes
B

self-assembly process:

CLC formation

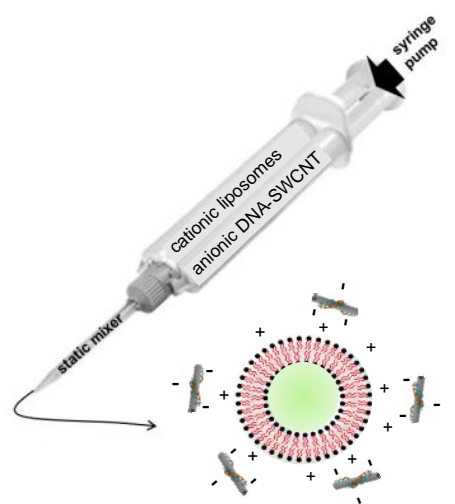

C

encapsulation of CLC

in a 3D hydrogel

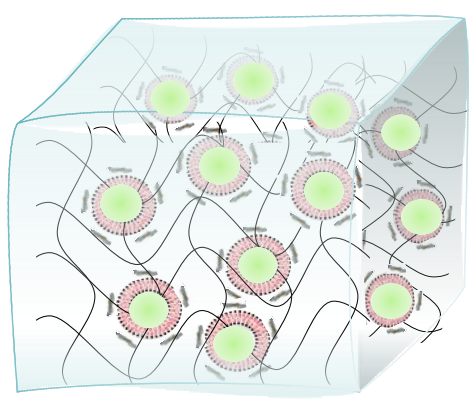

Schematic 1. DNA wrapped single walled carbon nanotubes and liposomes are selfassembled to carbon nanotube liposome complexes (CLCs) by electrostatic forces and encapsulated in a 3D hydrogel matrix. A. Nano-scale components of the system are shown: anionic DNA-wrapped SWCNT and cationic liposomes. B. DNA-wrapped SWCNTs and liposomes are mixed at different ratios using a syringe and static mixer and CLCs self-assemble at this step. C. CLCs are then encapsulated into a covalently crosslinked alginate hydrogel.

\section{Methods}

Materials Polycarbonate membranes (pore size $100 \mathrm{~nm}$ ), filter supports, 1,2-dioleoyl-snglycero-3-phosphocholine (DOPC); 2-dioleoyl-3-trimethylammonium-propane (DOTAP) in chloroform were purchased from Avanti Polar Lipids Inc. (AL, US). Raw powder SWCNTs produced by HiPco process were purchased from Nanointegris (QC, Canada). Sodium Alginate (Protanal LF20/40) of high molecular weight ( $250 \mathrm{kDa})$ was provided by FMC BioPolymers (Philadelphia, PA). Phosphate buffered saline (PBS) powder, $\mathrm{NaCl}$, 2-(N-Morpholino)ethanesulfonic acid hydrate (MES hydrate), adipic acid dihydrazide (AAD), 1-hydroxybenzotriazole (HOBt), 1-ethyl-3-(dimethylaminopropyl), carbodiimide (EDC), Sigmacote solution and Fluorescein Isothiocyanate-Dextran (FITC-Dex MW of 3 
$\mathrm{kDa})$ were purchased from Sigma Aldrich (MO, US). Desalted ss(GT) 15 oligomeric DNA and Cy5-ss(GT) 15 were purchased from Integrated DNA Technologies (IA, US).

Preparation of DNA-SWCNT Dispersions Single-stranded DNA was used to noncovalently wrap the SWCNTs and disperse them in aqueous solutions following a previously published method. ${ }^{33}$ For each dispersion, $1 \mathrm{mg}$ of raw HiPco nanotubes was added to $2 \mathrm{mg}$ of desalted $\mathrm{ss}(\mathrm{GT}) 15$ oligonucleotide in a microcentrifuge tube with $1 \mathrm{~mL}$ of $100 \mathrm{mM} \mathrm{NaCl}$. The mixtures were then ultrasonicated using a 1/8" tapered microtip (Sonics Vibracell) for $2 \mathrm{~h}$ at $40 \%$ amplitude, with an average power output of $8 \mathrm{~W}$, in a 0 ${ }^{\circ} \mathrm{C}$ temperature-controlled microcentrifuge tube holder. The dispersion was ultracentrifuged (Sorvall Discovery M120 SE) for $30 \mathrm{~min}$ at 250,000 $\mathrm{xg}$ and the top $80 \%$ of the supernatant was extracted. The concentration of the stock DNA-SWCNT dispersion (SWCNT solution) was determined by a previously described method. This was done by measuring the stock solution absorbance with a UV/vis/NIR spectrophotometer (Jasco, Japan) at $910 \mathrm{~nm}$ and using the extinction coefficient Abs910nm $=0.02554 \mathrm{~L} \mathrm{mg}^{-1} \mathrm{~cm}^{-1} .42,45$ ${ }^{47}$ To remove free DNA molecules, Amicon ultracentrifuge filters (Millipore Sigma) with $100 \mathrm{kDa}$ molecular weight cutoff were used. Filtration was repeated three times for each sample, and at each step, the pellets were resuspended in $100 \mathrm{mM} \mathrm{NaCl}$.

Liposome Fabrication \& Characterization Thin lipid film hydration method ${ }^{48}$ was used to form DOPC:DOTAP 1:1 liposomes. Briefly, lipids were mixed at 1:1 molar ratio in chloroform at $40 \mathrm{mM}$ total lipid and rotary evaporated (rotavapor R-215 Buchi) in a $50 \mathrm{~mL}$ round bottom flask to form a thin lipid film. The pressure was decreased from $300 \mathrm{mbar}$ to $200 \mathrm{mbar}$, and finally to $50 \mathrm{mbar}$ ( $30 \mathrm{~min}$ at each pressure). During this step, the rotating flask was kept in a water bath at $50^{\circ} \mathrm{C}$. After the thin lipid film formation step, 
flasks were kept under vacuum (25 mbar) overnight for complete drying. Then, $4 \mathrm{~mL}$ of the model drug solution (3 $\mathrm{kDa}$ FITC-Dex in deionized (DI) water) at $1 \mathrm{mg} / \mathrm{mL}$ was added to each flask. After 5 min of hydration at $45^{\circ} \mathrm{C}$, flasks were vortexed, and solutions were extruded at room temperature through a polycarbonate membrane (100 nm pores) using Avanti Extrusion System to form uniform-sized of unilamellar liposomes. Dynamic light scattering (DLS) was used to measure the size and polydispersity index (PDI) of the final liposome solution.

SWCNT-Liposome Complex (CLC) Fabrication and Characterization DNA-SWCNTS (at $0,20,50$ or $100 \mathrm{mg} / \mathrm{L}$ ) were mixed with FITC-Dex-loaded liposomes (at $5 \mathrm{mM}$ of lipid concentration). A syringe pump (NE Pump System Model NE-4000) and a two-barrel syringe were used to keep the mixing rate constant and ensure complete mixing of the SWCNT and liposome solutions. The samples and SWCNT solution were then analyzed using DLS to measure size, PDI, and zeta-potential. Cryo-transition electron microscopy (cryo-TEM) was conducted using a JEOL JEM-2100F TEM (Ma, US). It was operated at $200 \mathrm{kV}$ using a liquid nitrogen cooling stage Model 915, Gatan Inc. (CA, US). $10 \mathrm{~mL}$ of the sample was deposited onto a Quantfoil copper grid of 200 square mesh purchased from Electron Microscopy Sciences (PA, US). The sample grids were inserted in liquid ethane using a Vitrobot system (FEI Company, Hillsboro).

Integration of CLCs into 3D Hydrogels \& Passive Release Purified alginate was dissolved in MES buffer at 2.5 wt\% with $2.5 \mathrm{mM} \mathrm{AAD}$ crosslinker and $4.3 \mathrm{mM}$ HOBt. The alginate solution $(2 \mathrm{~mL}$ ) was then mixed with CLCs at $2.5 \mathrm{mM}$ lipid and $25 \mathrm{mg} / \mathrm{L}$ SWCNT $(2 \mathrm{~mL})$ using luer-lock syringes and luer-lock connectors. To ensure complete mixing, at least 20 passes were performed each time. EDC in MES buffer $(1 \mathrm{~mL})$ at $100 \mathrm{mg} / \mathrm{mL}$ was 
used to initiate crosslinking. Two silicone coated glass plates with $2 \mathrm{~mm}$ spacers were used for gel casting. Individual cylindrical $8 \mathrm{~mm} \times 2 \mathrm{~mm}$ gel disks were cut using biopsy punches (Integra Miltex, PA). A three-day rinse (9 times media change) was performed in PBS to remove any non-encapsulated drug and crosslinking residues. This rinsing step was also used as a purification step to remove any free SWCNT from the system. The gels were then kept in 24 well plates in $1 \mathrm{~mL}$ of PBS at room temperature in dark and media was changed daily.

Gels were exposed to $0.02 \%$ Triton-X 100 (TX-100) solution to disrupt liposomes and release their cargo on day 3 . Samples were collected daily and confocal microscopy of the hydrogels was performed at specific time points (day 3 and day 4) using laser scanning microscopy with a Zeiss LSM 700 confocal module. Epifluorescence observation with FITC filter was used with the diode laser with an excitation line at 488 nm. Zeiss ZEN 2011 software was utilized for image analysis. 3D z-stacks of xyz (350 $\mu \mathrm{m}$ '350 $\mu \mathrm{m}$ '250 $\mu \mathrm{m}$ ) was obtained using $10 \mu \mathrm{m}$ step size at day 0 to ensure uniform distribution of CLCs within the hydrogel with different SWCNT concentrations. To quantify FITC-Dex release, fluorescence spectra of the samples was measured using Cytation 3 Plate Reader with BioTek Gen5 software using the excitation wavelength of $490 \mathrm{~nm}$ and the emission wavelength of $520 \mathrm{~nm}$. Standard solutions were prepared with known concentrations of FITC-Dex and the standard curve was used for calculating unknown concentrations.

As SWCNTs can affect fluorescence properties of dyes, we performed a control test where different concentrations of DNA functionalized SWCNTs were mixed with a constant concentration of FITC-Dextran and incubated at room temperature for $1 \mathrm{~h}$. 
Examined concentrations were $20 \mathrm{mg} / \mathrm{L}, 10 \mathrm{mg} / \mathrm{L}$ and $5 \mathrm{mg} / \mathrm{L} \mathrm{SWCNT}$ in the final solution with a constant FITC-Dex concentration of $1 \mathrm{mg} / \mathrm{mL}$. A Cytation 3 Plate Reader with BioTek Gen5 software was used and fluorescence emission spectra was measured using excitation wavelength of $490 \mathrm{~nm}$.

Colocalization of SWCNTs and Liposomes To study colocalization of SWCNT and liposomes in CLCs, single stranded DNA was substituted with Cy5-ssDNA where a Cy5 dye was attached to 5' end of the DNA strand. All of the other parts of the procedure were followed similar to the previously described method: "DNA Wrapping of SWCNT". These Cy5-DNA-SWCNT were then used to fabricate CLCs at $50 \mathrm{mg} / \mathrm{L}$. FITC-Dex $3 \mathrm{kDa}$ at 0.5 $\mathrm{mg} / \mathrm{mL}$ was loaded into the liposomes prior to mixing with SWCNTs. These CLCs were then integrated into an alginate scaffold and rinsed for one day. Fluorescence confocal microscopy was performed using a Zeiss LSM 700 confocal. Epifluorescence observation with a Rhodamine filter with an excitation at $555 \mathrm{~nm}$ was followed with a FITC filter with an excitation line at $488 \mathrm{~nm}$. The middle image of the $z$-stack was used for colocalization analysis. The images from these two channels were overlaid and colocalization analysis was conducted with FIJI software using Coloc 2 plugin.

Confocal Raman Imaging Gels were imaged using a WiTec Alpha300 R confocal Raman microscope (WiTec, Germany) equipped with a Zeiss EC Epiplan - Neofluar 10x /0.25 objective, a $785 \mathrm{~nm}$ laser source set to $30 \mathrm{~mW}$ sample power, and a WiTec UHTS 300 CCD detector with a 300 lines/mm grating. The Raman Z-stacks were obtained in 2.5 X $2.5 \mu \mathrm{m}$ intervals with $17.5 \mu \mathrm{m}$ depth between slices and a 0.2 second/spectrum integration time to construct hyperspectral Raman volumes within the gels. A global background subtraction and cosmic-ray removal was performed using WiTec Control 5.2 
software on all acquired confocal Raman data. A calibration curve was obtained by recording spectra of known SWCNT concentrations serially diluted in a single pixel volume using identical acquisition settings. Using custom Matlab codes, the G-band from each spectrum was fit to a Lorentzian curve and the intensity was correlated to the known SWCNT concentration to produce linear fit coefficients. The G-band of all spectra from the confocal Raman Z-stacks were fit to Lorentzian curves, the intensity was extracted, and the calibration coefficients were applied to construct 3D concentration maps of SWCNTs in the gels.

Mechanical Testing of Hydrogels Compression tests were performed on hydrogels using an Instron Model 3345 (Norwood, MA). Hydrogels were fabricated and fully swollen in PBS for three days before the tests. The stress vs. strain of each gel $(8 \mathrm{~mm} \times 2 \mathrm{~mm})$ was recorded while the gel was compressed at a rate of $2 \mathrm{~mm} / \mathrm{min}$ to up to $70 \%$ strain. Three gels were tested for each condition. Young's moduli were calculated using the initial linear portion of the curve and the strain of failure was defined as the highest strain before the failure (the drop in compressive stress).

SEM imaging of CLC and alginate gels CLC and alginate gels were imaged using scanning electron microscopy to visualize gel's porous structure. To prepare the samples for SEM imaging, each gel was frozen at $-20{ }^{\circ} \mathrm{C}$ overnight. Gels were then lyophilized at 0.05 mbar and $-50 \stackrel{\circ}{ } \mathrm{C}$ for one day. Gels were then cross sectioned using a sharp razor blade, sputter coated by gold (coating thickness of $18 \mathrm{~nm}$ ). Samples were imaged using a Zeiss SIGMA VP field emission scanning electron microscope (FE-SEM). EverhartThornley detector was used with $3 \mathrm{kV}$ acceleration voltage and chamber pressure was set at $5 \times 10^{-6}$ Torr. 
Heating of CLC Solutions using an NIR Laser We conducted all of the heating/stimulating experiments using a laser module with fiber coupling at $1122 \mathrm{~nm}$ (Model MIL-H-1122-1W) (Changchun New Industries, China). Samples were kept in a 24 well plate during the experiment ( $1 \mathrm{~mL}$ in each well). The laser was set up to have a $1 \mathrm{~cm}$ distance from the well. A water bath was set at $37^{\circ} \mathrm{C}$ and plates were kept on the water using a stand prior to starting of the experiment (to reach equilibrium) and during the experiment. Four different SWCNT concentrations $(0,10,20$ and $30 \mathrm{mg} / \mathrm{L})$ were heated using the NIR laser at $8.85 \mathrm{~kW} / \mathrm{m}^{2}$. The temperature was recorded using a USB TC-08 thermocouple data logger (Pico Technology, UK) with 10 seconds time intervals. These concentrations were selected because they correspond to the final concentration of SWCNT in the gels using initial SWCNT concentrations of $0,25,50$ and $75 \mathrm{mg} / \mathrm{L}$. A pulsed heating experiment was conducted using the $20 \mathrm{mg} / \mathrm{L}$ solution where the laser was set at 60 seconds on, 300 seconds off and the pulse was repeated 5 times.

Stimulated Release Studies CLCs were fabricated and loaded with $0.5 \mathrm{mg} / \mathrm{mL}$ FITCDex $3 \mathrm{kDa}$ using the $50 \mathrm{mg} / \mathrm{L}$ SWCNT solution as described previously. Hydrogels were fabricated following the previously described method with CLCs or liposomes. The hydrogels were cut in $8 \mathrm{~mm}$ diameter $2 \mathrm{~mm}$ thick cylinders and rinsed 9 times in 3 days prior to start of the experiment. Then, each gel was kept in a well of a 24 well plate with $1 \mathrm{~mL}$ PBS for release studies. One set of gels $(n=3)$ were stimulated using the $1122 \mathrm{~nm}$ laser at $8.85 \mathrm{~kW} / \mathrm{m}^{2}$ at $37^{\circ} \mathrm{C}$ for $1 \mathrm{~h}$ while another set of gels (control at $37^{\circ} \mathrm{C}$ ) were not stimulated. One set of liposome gels $(n=3)$ were exposed to $0.2 \%$ TX-100 solution to release all of the liposome cargo. Release samples were acquired immediately before and 1 day after stimulation (to provide enough time for diffusion from the gel). In another 
experiment, three sets of CLC encapsulating gels (control, stimulated and TX-100) were tested for different time durations (15, 30 or $45 \mathrm{~min})$. Samples were acquired immediately before and after stimulation for all of the conditions. Although sampling right after stimulation did not provide enough time for all of the drug released from CLCs to diffuse out of the hydrogel, it aimed to show differences in instant release for the different NIR stimulation time durations.

Swelling Ratio Measurement before and after NIR Stimulation Swelling ratio of CLC gels was measured for two set of gels: 1 . control CLC gels at $50 \mathrm{mg} / \mathrm{L}$ that were not stimulated and 2. stimulated gels: exposed to NIR laser stimulation at $8.85 \mathrm{~kW} / \mathrm{m}^{2}$ for 1 h. Gels were formed following the previously mentioned method and punched into individual cylindrical disks $(8 \mathrm{~mm} \times 2 \mathrm{~mm}$ ). Each gel was fully swollen and rinsed 9 times before the tests. The weights of the swollen gels were measured after removal of excess solution by a filter paper. The gels were then frozen overnight at $-20^{\circ} \mathrm{C}$ and lyophilized at 0.05 mbar for a day. The weights of dry gels were measured right after their removal from the lyophilizer. Swelling ratio (SR) was calculated using the following formula:

$S R=\frac{W_{S}-W_{d}}{W_{d}}$

where $W_{s}$ and $W_{d}$ represent weights of the swollen and dried gels, respectively.

Cytotoxicity of CLC gels in vitro To assess gel and laser stimulation cytotoxicity in vitro, Annexin V/ Propidium lodide apoptosis assay was used on macrophages. RAW 264.7 TIB-71 cells (ATCC, Manassas, VA, USA) were cultured under standard incubation conditions at $37^{\circ} \mathrm{C}$ and $5 \% \mathrm{CO} 2$ in cell culture medium containing sterile filtered highglucose DMEM with 10\% heat-inactivated FBS, 2.5\% HEPES, 1\% L-glutamine, $1 \%$ penicillin/ streptomycin, and $0.2 \%$ amphotericin B. Media components were acquired from 
Gibco. RAW 264.7 macrophages were cultured until $80 \%$ confluency in 24 -well plates, at which media $(1 \mathrm{~mL})$ was replaced and CLC gels $(8 \mathrm{~mm}$ diameter and $2 \mathrm{~mm}$ thick, rinsed 9 times) were added to each well. Gels were either stimulated using a $1122 \mathrm{~nm}$ laser at $8.85 \mathrm{~kW} / \mathrm{m}^{2}$ or incubated without stimulation for $1 \mathrm{~h}$. Cells were immediately collected from each well and stained with annexin V and propidium iodide (Dead Cell Apoptosis Kit V13242, Invitrogen) following the manufacturers protocol. Fluorescence images of the stained cells were acquired using a Cellometer Vision CBA Image Cytometer (Nexcelom Bioscience) and images were analyzed using ImageJ and custom MATLAB codes. Three gel samples were used for each condition and total cells of $n>6,700$ were imaged in histograms. Fluorescence data were gated based on control cells cultured without gel addition. For this non-gel control, 4 well plates were used with total cells of $n>6,700$. A gel from each group of stimulated or non-stimulated was imaged to capture any visual or macroscopic physical changes.

Statistical Analyses and Data Representation All quantitative data are reported as means \pm standard deviation of three different samples. Analysis of variance (ANOVA) was used with Tukey's post hoc tests for multiple comparisons to evaluate statistically significant differences when multiple groups were compared. When a single pair of conditions were analyzed, Student's t tests were used. $p$ values less than 0.05 was the benchmark for statistically significant differences. Symbols ${ }^{*},{ }^{* *}$, and ${ }^{* * *}$ indicate statistical significance with $p<0.05,0.01$, and 0.001 , respectively. No statistically significant difference is indicated by an "n.s." ( $p>0.05)$.

\section{Results \& Discussion}




\section{SWCNT-Liposome Complex (CLC) Fabrication}

We fabricated SWCNT-liposome complexes (CLCs) through self-assembly by mixing DNA-functionalized SWCNTs with cationic liposomes. To study the effect of SWCNT solution concentration on the CLCs' structures, four different concentrations of SWCNT solution were tested: $0,20,50$ and $100 \mathrm{mg} / \mathrm{L}$. We used a previously published method ${ }^{33}$ to achieve uniformly dispersed solutions of Hipco SWCNTs. In their raw form, SWCNTs are highly hydrophobic and are insoluble in water. Sonication of SWCNTs with DNA and ultracentrifugation to remove aggregates results in a dark, ink-like solution of dispersed DNA-SWCNT conjugates. Successful conjugation is further confirmed by the appearance of multiple peaks in the NIR and visible range of their absorbance spectrum ${ }^{41,42}$ (Figure S1). As shown in Figure $1 \mathrm{~A}$, the average diameter of the liposomes did not change significantly when the $20 \mathrm{mg} / \mathrm{L}$ SWCNT solution was introduced. However, when the SWCNT solution's concentration was increased to $50 \mathrm{mg} / \mathrm{L}$ and $100 \mathrm{mg} / \mathrm{L}$, the average diameter significantly changed compared to the lower concentrations as well as compared to the bare liposome (i.e. $0 \mathrm{mg} / \mathrm{L}$ ) (Figure $1 \mathrm{~A}(\mathrm{i})$, black bars). It is important to note that the polydispersity index also did not change significantly when $20 \mathrm{mg} / \mathrm{L}$ of SWCNTs were used. The polydispersity index increased significantly compared to the bare liposomes (i.e. $0 \mathrm{mg} / \mathrm{L}$ ) when $50 \mathrm{mg} / \mathrm{L}$ or $100 \mathrm{mg} / \mathrm{L}$ SWCNT solutions were used (Figure $1 \mathrm{~A}(\mathrm{i})$, green bars). Zeta potentials of the CLC solutions were also measured, and a decreasing trend was observed as the SWCNT concentration increased. The zeta potential of SWCNT solution at $50 \mathrm{mg} / \mathrm{L}$ was $-39.8 \mathrm{mV}$ with standard deviation of 5.57 . Similar to diameter and PDI, no significant changes were noticed when zeta potential of $20 \mathrm{mg} / \mathrm{L}$ was compared with the control (i.e. $0 \mathrm{mg} / \mathrm{L}$ ). However, zeta potential of CLCs at 
$50 \mathrm{mg} / \mathrm{L}$ and $100 \mathrm{mg} / \mathrm{L}$ was significantly decreased compared to the control. Despite this decrease and significant change, the value of the zeta potential stayed positive. This can be attributed to the positive charge of the head groups of DOTAP lipids which are used in the fabrication of the self-assembled liposomes. As the DNA functionalized SWCNTS have a negative charge, they are electrostatically attracted to these positively charged lipids and form self-assembled CLCs. SWCNTs partially coated the liposomes and as a result led to partial charge screening of cationic DOTAP headgroups; however, they did not change the total charge of the solution to a negative value. When the concentration of SWCNTs was increased further (e.g. $200 \mathrm{mg} / \mathrm{L}$ ), macroscopic aggregations formed, and the solution was unstable. The net positive charge of CLCs is desirable as it facilitates their prolonged encapsulation within the 3D alginate hydrogel which is a negatively charged polymer and limits leakage of CLCs out of the hydrogel. It was concluded that the structures of CLCs were defined mainly by the ratio of SWCNTs to liposomes and therefore by changing the SWCNT's solution concentrations while keeping liposome's solution concentration constant, different complexes were formed.

Cryo-TEM imaging was performed to visualize the CLC structures at 50 and $100 \mathrm{mg} / \mathrm{L}$ SWCNT concentrations. As shown in Figure 1B, complex and abnormal shapes were observed at $50 \mathrm{mg} / \mathrm{L}$ and $100 \mathrm{mg} / \mathrm{L}$ compared to the regular unilamellar liposomes at 0 $\mathrm{mg} / \mathrm{L}$ (the left image). As SWCNTs have very low contrast in cryo-TEM imaging, single SWCNTs cannot be directly observed but are rather detected by the effects that they apply on other higher contrast moieties (e.g. liposomes) ${ }^{41}$ Although these structures were complex in shape, they still demonstrated characteristic liposomal bilayers and did not 
show macro aggregation when analyzed by DLS. This indicates that SWCNTs were not disrupting the bilayers, signifying the preservation of liposomal integrity and the ability to encapsulate drugs. This was further verified in drug release experiments.

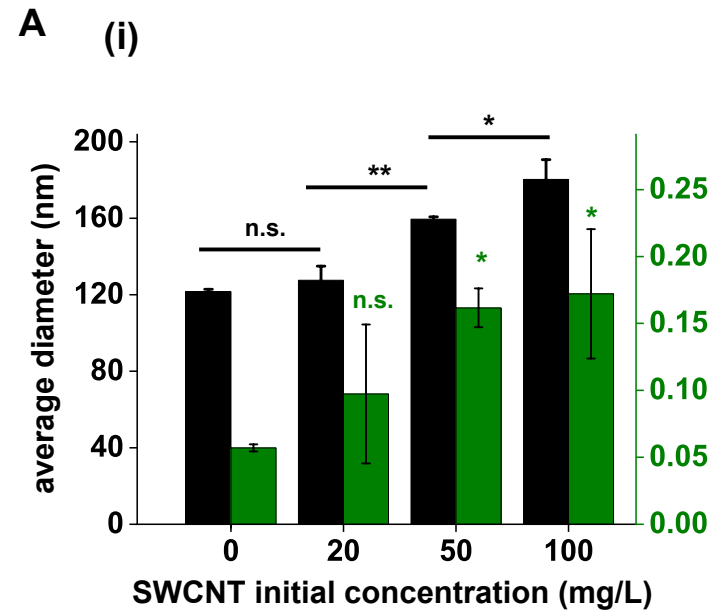

B
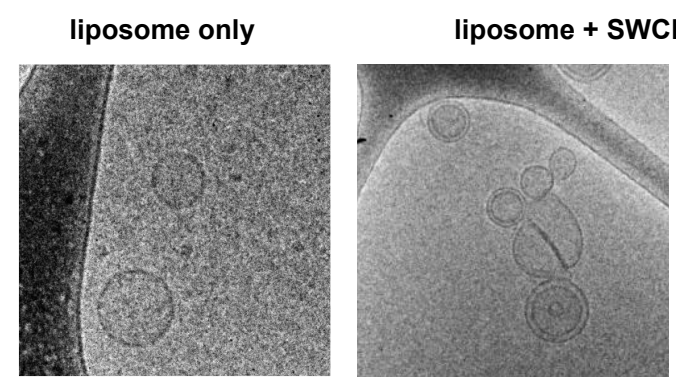

(ii)

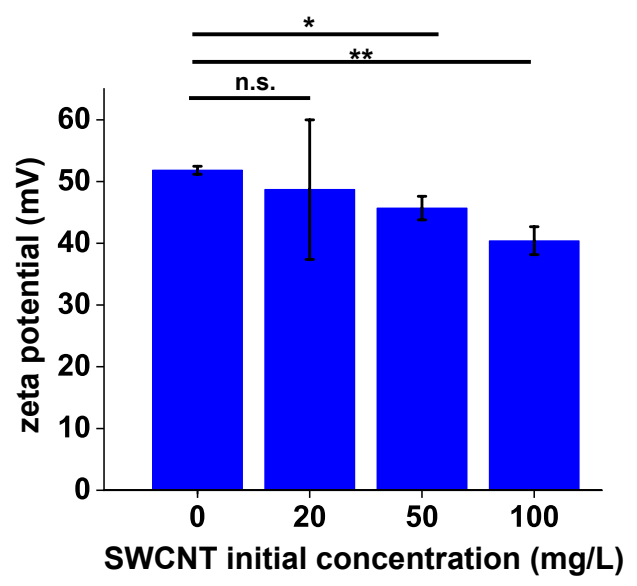

liposome + SWCNT at $100 \mathrm{mg} / \mathrm{L}$
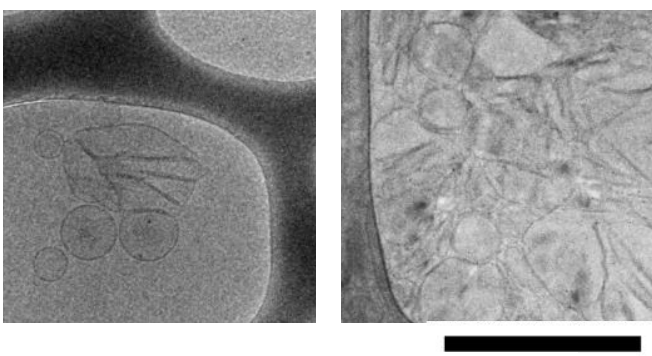

$200 \mathrm{~nm}$

Figure 1. CLCs with different properties (size and charge) are formed by changing SWCNT to lipid ratio A. (i) Statistical comparison of average diameters and PDIs for different CLCs. (ii) Statistical comparison of zeta potentials for different CLCs. B. Cryo-TEM images of liposomes and CLCs at $50 \mathrm{mg} / \mathrm{L}$ and $100 \mathrm{mg} / \mathrm{L}$ are shown $(\mathrm{n}=3)$.

\section{Integration of CLCs into 3D Hydrogels \& Passive Release}


The fabricated CLCs were integrated into 3D alginate hydrogels to enhance stability and enable on-demand localized drug delivery. CLCs in gels were imaged using confocal fluorescence microscopy for all formulations (Figure 2A). The 3D z-stack of images at day 2 showed uniform distributions of CLCs in the 3D hydrogels (Figure S2). We confirmed that FITC-Dex did not interact with the SWCNTs and result in quenched fluorescence at the specified concentrations (Figure S3). Cumulative passive release rates were less than $2 \%$ for all of the conditions before the addition of TX-100 (Figure 2B). It is important to note that the rates of passive release for CLCs with $20 \mathrm{mg} / \mathrm{L}$ SWCNT was significantly higher than the rate of passive release for bare liposome $(0 \mathrm{mg} / \mathrm{L})$ in the first two day (Figure $2 \mathrm{C}(\mathrm{i})$ ). The passive release rate of concentrations $50 \mathrm{mg} / \mathrm{L}$ and $100 \mathrm{mg} / \mathrm{L}$ was not significantly different from bare liposome in the first 2 days. This result can be explained considering high PDI at $20 \mathrm{mg} / \mathrm{L}$ and complex shapes of CLCs that could lead to significantly higher leakage rates. As the TX-100 solution was added to disrupt the liposomal structures, enhanced release was observed for all of the conditions (Figure $2 A \& B)$. Although this enhanced release rate was slightly higher for $50 \mathrm{mg} / \mathrm{L}$ and $100 \mathrm{mg} / \mathrm{L}$ SWCNT, no statistically significant differences were observed for these concentrations compared to the lower concentrations (Figure 2C(ii)). Samples continued to release FITCDex from this time point (day 2) up to day 6 . As the drug was released from the liposome or CLC structures, some amount of the drug was trapped within the 3D hydrogel structure (day 2 to day 6) and was slowly released through a constrained diffusion process. This slow diffusion for several days is crucial for some applications as a sustained release is required rather than a burst release for these applications. ${ }^{49}$ These results suggest that 
this system can provide a sustained release starting at a delayed and controlled time point (e.g. day 2 in this experiment or the time of stimulation for stimulated release).

The release of encapsulated therapeutic components inside of a hydrogel matrix can be affected by swelling-dependent changes in diffusivity. Therefore, to understand any effects of NIR stimulation on this property, we measured swelling ratio of two set of gels: (1) control CLC gels at $50 \mathrm{mg} / \mathrm{L}$ that were not stimulated and (2) CLC gels exposed to NIR laser stimulation at $8.85 \mathrm{~kW} / \mathrm{m}^{2}$ for $1 \mathrm{~h}$. A represented gel from each group was also imaged to evaluate any physical changes caused by NIR stimulation (Figure S4A).

There were no significant differences between swelling ratios of control or NIR stimulated gels (Figure S4B). This indicates that in the stimulated release studies, release of cargo from gel would be caused by disruption of the CLC structures followed by diffusion of the cargo from the gel. 

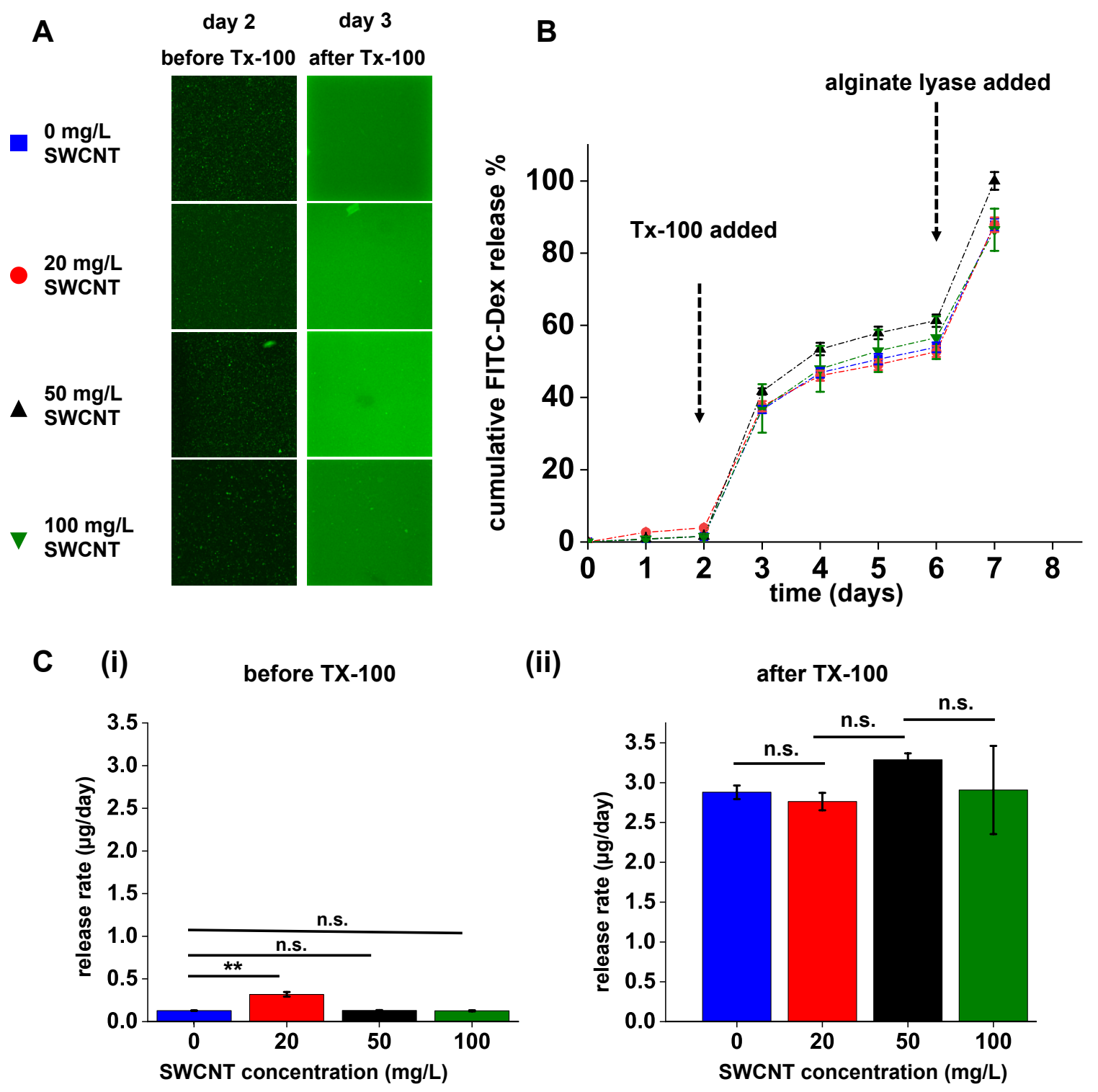

(ii)

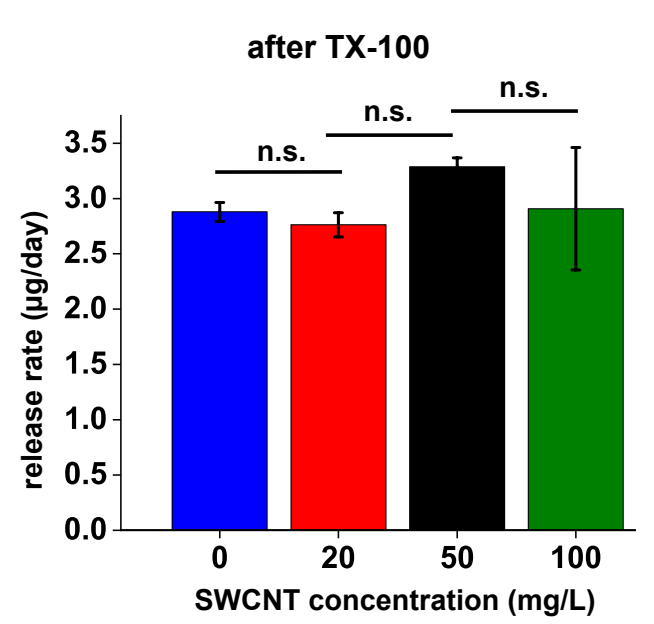

Figure 2. CLCs were integrated into 3D hydrogel structures and imaged using confocal microscopy. A. Images of the middle layer $(z=100 \mathrm{~mm})$ of a $z$-stack for different CLCs in alginate are shown before (day 2) and after (day 3) addition of $0.02 \%$ TX-100. B. Percentage of cumulative FITC-Dex release vs. time from $50 \mathrm{mg} / \mathrm{L} \mathrm{CLC}$ loaded in alginate hydrogels are demonstrated. C. Statistical comparison of release rates of FITC-Dex from CLCs that were made using different DNA-SWCNT concentrations before the addition of $0.02 \%$ TX-100 (day 
0-2). (ii) Statistical comparison of release rates of FITC-Dex from CLCs that were made using different DNA-SWCNT concentrations after the addition of $0.02 \%$ TX-100 (day 2-3) $(n=4)$.

\section{CLC Distribution in the 3D Hydrogel and Hydrogel Characterization}

As shown in Figure 3A, the hydrogels were a uniform light gray color (CLC integrated gel, "CLC gel", compared to liposome only gel, "lip gel") with no visual signs of aggregation. This uniform gray color verified relatively even distribution of the CLCs within the 3D hydrogel with no macroscopic aggregations. SEM imaging was used to visualize the porous structure of control alginate gels and CLC gels and confirmed no noticeable differences in porosity of these gels, indicating that CLC encapsulation did disturb the covalent crosslinking process of the alginate gels (Figure 3B). The mechanical properties of lip gels and CLC gels at $50 \mathrm{mg} / \mathrm{L}$ DNA-SWCNT were analyzed. As shown in Figure $3 \mathrm{C}$, compressive stress vs. strain was measured for the different gels. While CLC integrated gels had similar Young's moduli compared to liposome integrated gels (Figure 3D(i)); a significantly higher strain of failure was recorded for CLC Gels compared to lip gels (Figure 3D (ii)). This result is consistent with previous studies that showed enhancement of mechanical properties upon the addition of SWCNTs, ${ }^{50}$ and has been attributed to matrix-fiber stress transfer. Fiber length, aspect ratio, dispersion, and alignment determine the reinforcement effectiveness. Specifically, it is important to have a dispersed SWCNT in the polymer network to achieve efficient load transfer and enhanced mechanical properties. ${ }^{51}$ 
A

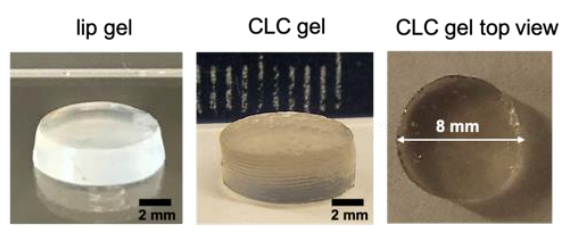

B
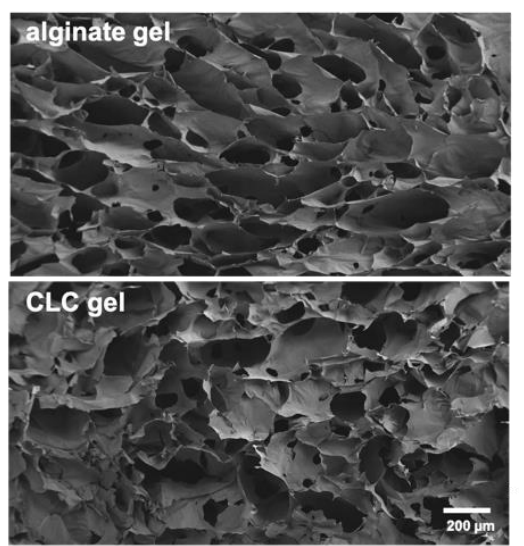

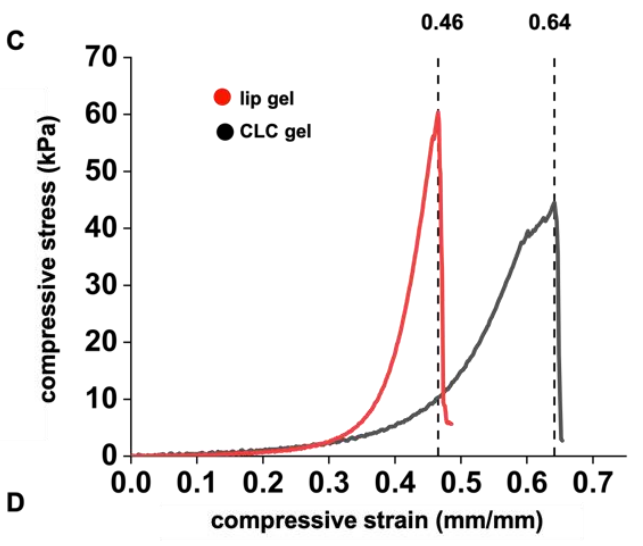

(i)

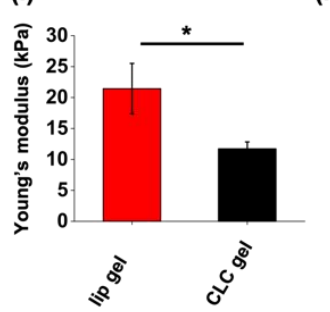

(ii)

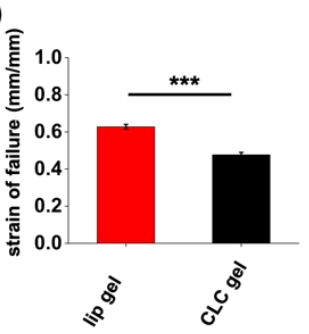

Figure 3. CLCs distribution in an alginate gel and mechanical properties are shown. A.

Photos of Lip-gel and CLC-gel (8 $\mathrm{mm}$ diameter $2 \mathrm{~mm}$ thick) at the DNA-SWCNT

concentration of $50 \mathrm{mg} / \mathrm{L}$ is shown. B. SEM images of control alginate gel and CLC gel showed no significant differences in porous structure. C. Compressive stress vs. strain curve for a representative CLC gel and a lip gel is demonstrated. D. (i) Statistical comparison of Young's modulus of CLC gels vs. lip gels is shown. (ii) Statistical comparison of the strain of failure of CLC gels vs. lip gels are shown $(n=3)$.

Colocalization of the SWCNTs and liposomes was examined by using confocal fluorescence microscopy. SWCNTs were dispersed with a fluorescently-tagged Cy5-DNA strand (red) and FITC-Dex (green) was used as the model drug loaded inside of the liposomes. Imaging of the fluorescently-tagged CLC gels was performed to ensure that these moieties are not separated when integrated into the hydrogel construct. Figure S5 shows an overlaid confocal image and a qualitative colocalization analysis graph 
corresponding to that image. Results showed an average $70 \%$ colocalization. To further evaluate SWCNT distribution within the hydrogel, hydrogel volumes of $10^{6} \mathrm{~mm}^{3}$ were imaged using confocal Raman microscopy. The intensity of the G-band spectral feature, which is linearly correlated to SWCNT concentration, ${ }^{33,52,53}$ was used to visualize the localized SWCNT concentration within the gel and the volumetric concentration of SWCNTs in the gel was determined (Figure 4). A representative Raman Spectra of SWCNT at a random layer and the average of Raman Spectra of all layers are shown in Figure S6. There were no significant differences between the average Raman spectra and the single layer Raman spectra.

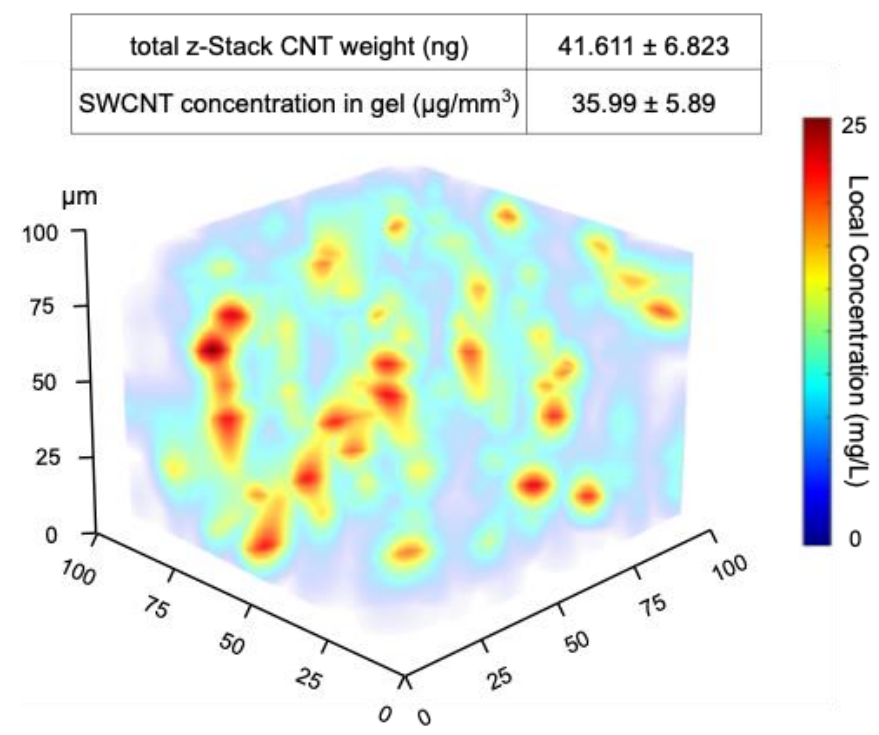

Figure 4. 3D confocal Raman concentration map of SWCNT G-band intensity represents localized SWCNT concentrations within a CLC integrated hydrogel (initial $50 \mathrm{mg} / \mathrm{L}$ ) and the volumetric concentration of SWCNTs in the gels is calculated $(n=5)$.

\section{Heating of CLC Solutions using an NIR Laser}


To evaluate the heating efficiency of the CLCs at specified wavelengths, absorbance spectra were acquired (Figure 5A). As expected, absorbance increased with SWCNT solution concentration and several distinct peaks, each representing a distinct SWCNT chirality ${ }^{40,47}$ were observed in the NIR range (Figure S1). For instance, the measured spectra confirm the presence of chiralities of $(9,4),(8,6)$ and $(8,7)$-SWCNTs in these samples. While some methods are available to separate single chiralities of SWCNTs, the efficiency of these separation processes are often very low. ${ }^{54}$ Here, we focused on the most pronounced peak, i.e. the $(9,4)$-SWCNT $\sim 1125 \mathrm{~nm}$. It is important to note that a peak around 1200 was also observed (the $(8,6)$-SWCNT). However, as the deionized water (DI) absorption is also significantly higher at this wavelength (pink line), it was not chosen for stimulation experiments.

We next examined the rate of heating of the SWCNT solutions due to laser illumination. A $1 \mathrm{~W}$ total power $1122 \mathrm{~nm}$ laser $\left(8.85 \mathrm{~kW} / \mathrm{m}^{2}\right)$ was used for all heating experiments with the distance between samples and the laser tip held constant at $1 \mathrm{~cm}$. All experiments were conducted in a $37^{\circ} \mathrm{C}$ water bath. As shown in Figure $5 \mathrm{~B}(\mathrm{i})$, by increasing SWCNT concentration, $\Delta \mathrm{T}\left({ }^{\circ} \mathrm{C}\right)$ vs. time increased. The maximum $\Delta \mathrm{T}$ 's were compared for the different SWCNT concentrations and a statistically higher maximum $\Delta \mathrm{T}\left({ }^{\circ} \mathrm{C}\right)$ was obtained for a higher SWCNT concentration compared to a lower concentration (Figure 5B(ii)). To understand the kinetics of the heating dissipation phenomena, a pulsed heating of 60 seconds on, 300 seconds off was applied on the SWCNT solution at $20 \mathrm{mg} / \mathrm{L}$. As shown in Figure $5 \mathrm{C}$, the temperature reached $46^{\circ} \mathrm{C}$ by the first 60 second laser pulse. However, when the laser was turned off, the heat quickly dissipated, and the temperature approached $37^{\circ} \mathrm{C}$ in less than 300 seconds. This trend was repeated in the next on and 
off cycles. Quantification of average slopes of heating and cooling was conducted and verified similar heating and cooling for all of the cycles (Figure S7).

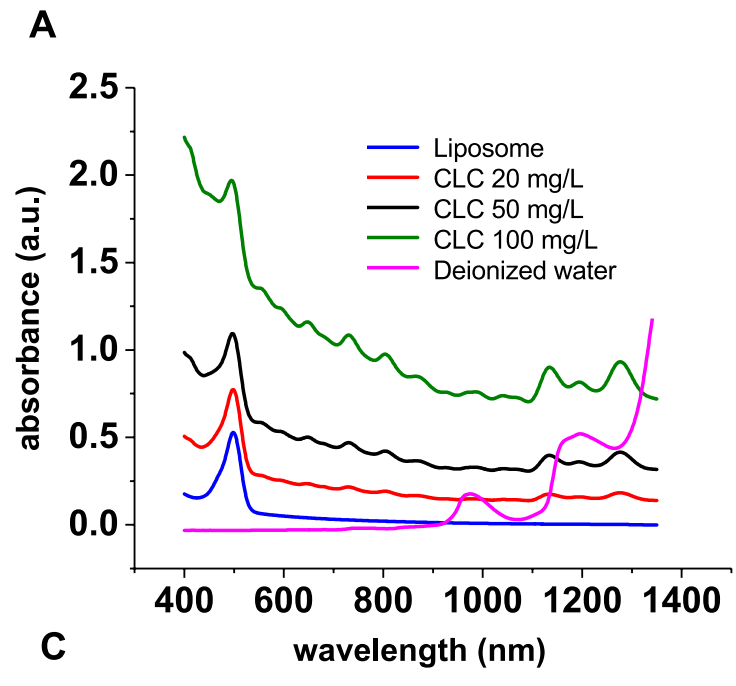

B
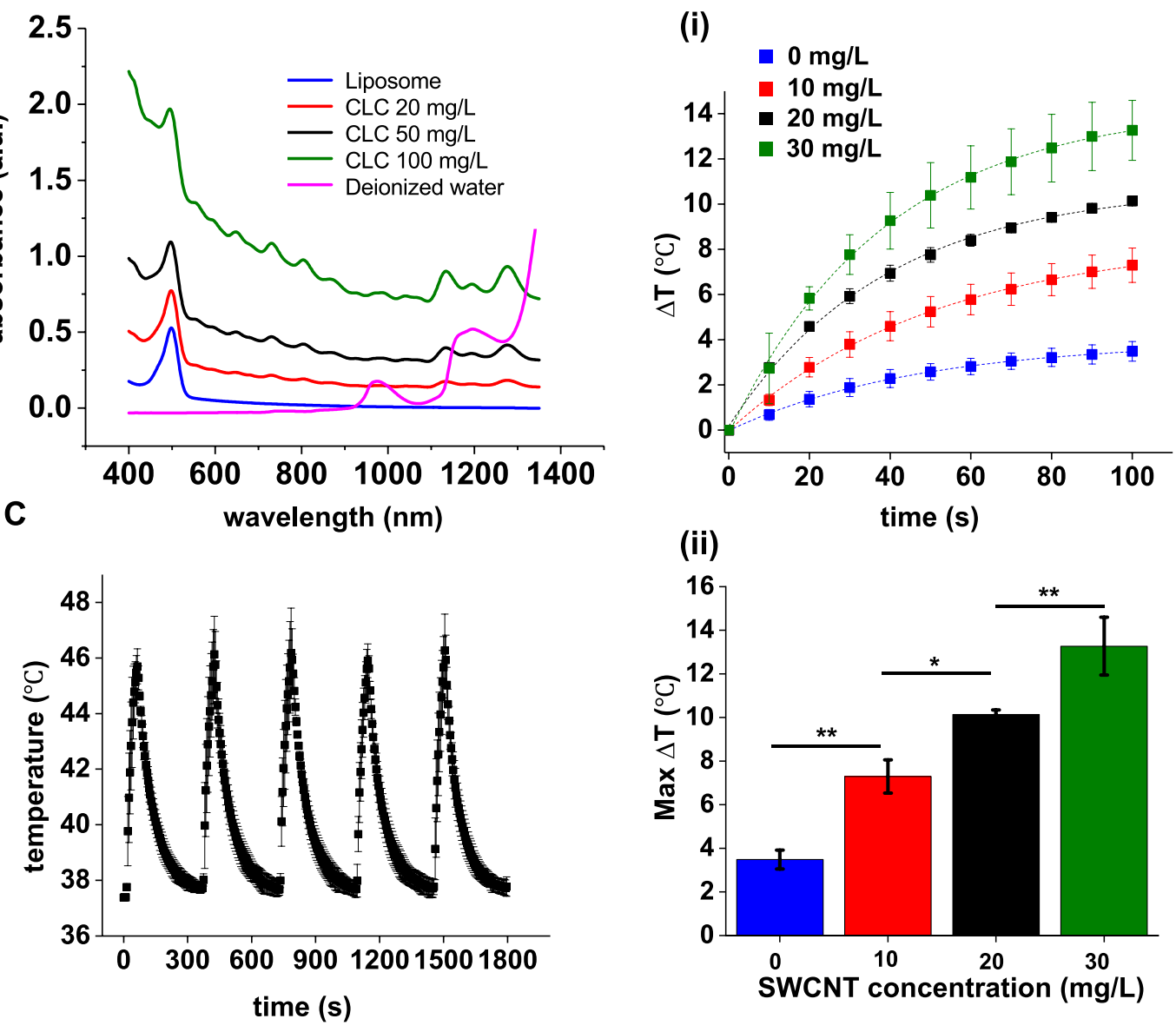

Figure 5. Absorbance spectra and heating rate of CLCs are demonstrated. A.

Absorbance spectra of CLCs at different SWCNT concentrations. B. (i) $\triangle T\left({ }^{\circ} \mathrm{C}\right)$ of SWCNT solutions vs. time at different concentrations are shown for 100 seconds heating at $1122 \mathrm{~nm}$, $1 \mathrm{~W}$. (ii) Statistical comparison of maximum $\Delta \mathrm{T}\left({ }^{\circ} \mathrm{C}\right)$ for different SWCNT concentrations. C. Temperature vs. time is shown for pulsed heating ( 60 seconds on, 300 seconds off) for the SWCNT solution at $20 \mathrm{mg} / \mathrm{L}(\mathrm{n}=3)$. 


\section{Stimulated Release Studies}

Finally, we demonstrated the stimulated release of FITC-Dex (3 kDa) from CLCs in a hydrogel using an $1122 \mathrm{~nm}$ laser. CLCs at $50 \mathrm{mg} / \mathrm{L}$ SWCNT were used for all of the stimulated experiments for CLC encapsulated gels. As shown in Figure 5A, each gel was stimulated at $1 \mathrm{~W}$ using an $1122 \mathrm{~nm}$ laser for $1 \mathrm{~h}$ and its release was compared to a control (same gel with no stimulation). Significantly higher amounts of FITC-Dex (3 kDa) were released from the laser stimulated gels compared to non-stimulated control gels (red bar compared with blue bar in Figure 5A(ii)). Release from liposome-encapsulated gels (with no SWCNT) was also measured and no significant difference was noticed for release from liposomes in gels with or without stimulation (purple bar compared with green bar). Tx-100 solution was used as a positive control to release all the cargo (black bar in Figure $5 \mathrm{~A}(\mathrm{ii}))$. This experiment shows that $1 \mathrm{~h}$ of stimulation at $1122 \mathrm{~nm}$ leads to release rates comparable with release from gels exposed to $T x-100$ and suggests that shorter stimulation durations can be used to stimulate release from CLCs in gel. To understand the effect of stimulation duration on release, a few different and shorter stimulation times were applied (i.e. 15, 30 and $45 \mathrm{~min}$ ) on CLC gels with three different conditions: control, stimulated and TX-100.

Adding $0.02 \% \mathrm{TX}-100$ solution to the gels resulted in significantly higher release rates compared to control or stimulated gels for all the stimulation durations (Figure 5B, black bars compared to blue and red bars). This significantly higher release rate was expected as TX-100 disrupts the liposomal bilayers and leads to a total release of the encapsulated drug. While different durations did not have a significant effect on the release rate from the control group, the longest stimulation time ( $45 \mathrm{~min}$ ) had a significantly higher release 
rate compared to the shorter stimulation times (30 $\mathrm{min}$ and $15 \mathrm{~min}$ ). Although there was not a significant difference between the release of $15 \mathrm{~min}$ and $30 \mathrm{~min}$ stimulations, $30 \mathrm{~min}$ stimulation caused slightly higher release compared to the 15 min stimulation and there does appear to be a manifest trend of increased release vs. NIR stimulation duration (Figure 5B(ii): upward "stairstep" vs. duration). Thus, it may be possible to externally regulate the amount of drug release from these structures through the duration of NIR stimulation. Additionally, while not demonstrated here, laser could also provide a means to externally regulate the amount of delivered payload triggered by stimulation events. It is of note that all of the stimulations used here caused a bulk temperature increase of less than $4{ }^{\circ} \mathrm{C}$ (keeping the bulk temperature below $42{ }^{\circ} \mathrm{C}$ ). This could significantly prevent tissue damage from heating and could also help preserve the bioactivity of encapsulated and delivered payloads. It is known that bulk temperatures of more than $42{ }^{\circ} \mathrm{C}$ (i.e. $46^{\circ} \mathrm{C}$ or $49{ }^{\circ} \mathrm{C}$ ) can lead to permanent cell damage and cause tissue toxicity. .55 If desired, the CLC gel system can be modified to show a combined photothermal therapy and chemotherapeutic delivery for cancer therapy. 
A

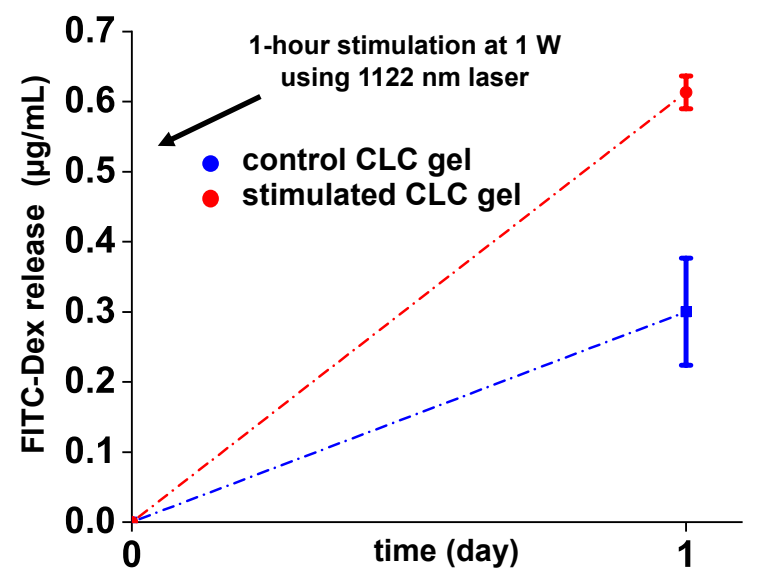

(i)

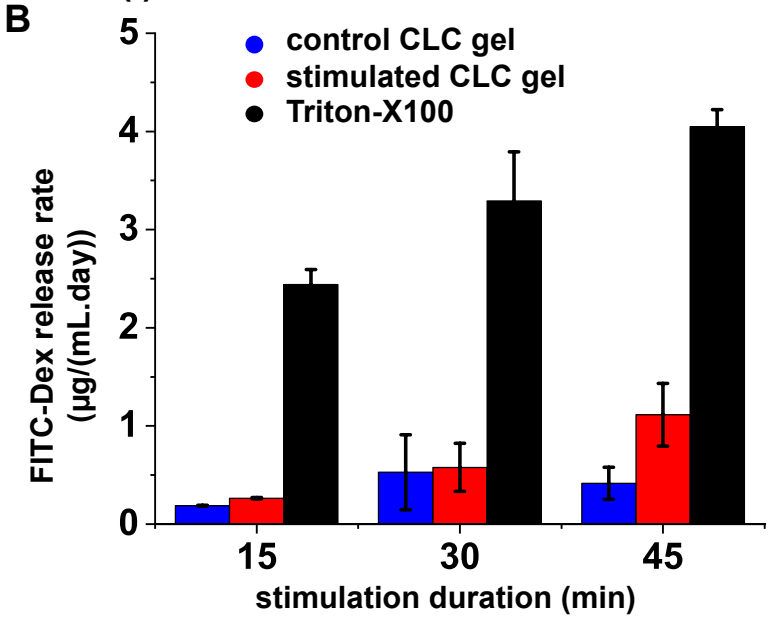

(ii)
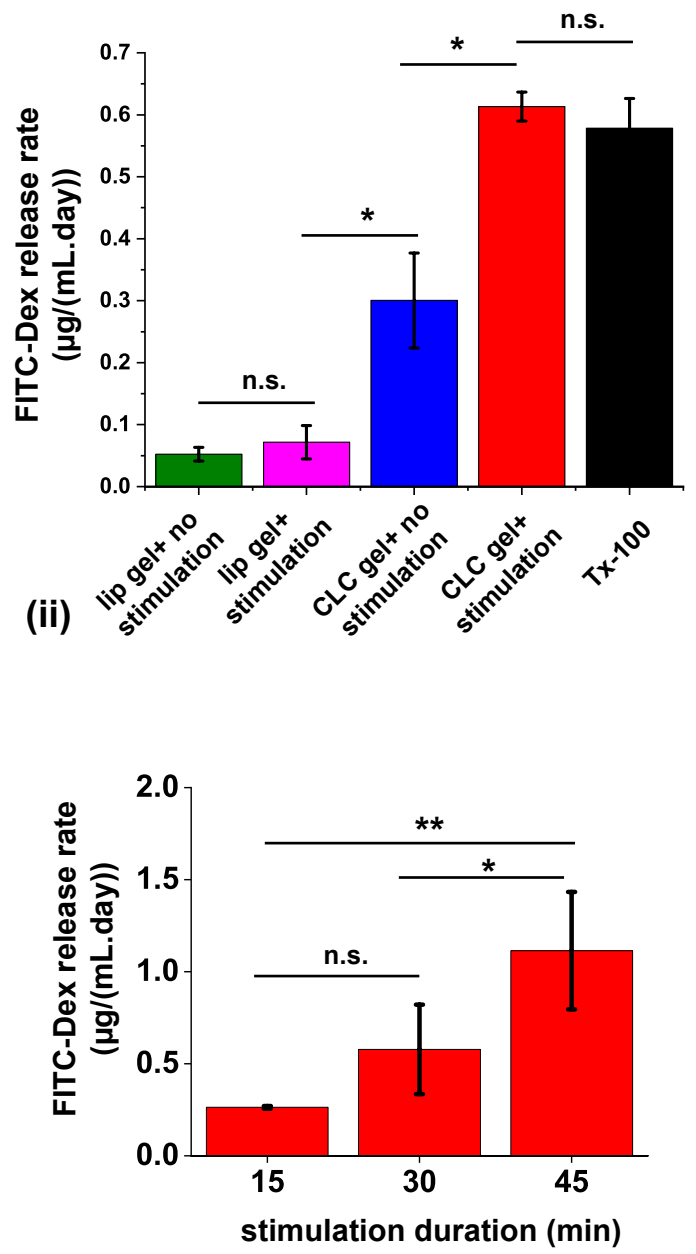

Figure 6. FITC-Dex release from CLCs in alginate hydrogels could be stimulated using NIR laser. A. (i) Cumulative FITC-Dex release when $1 \mathrm{~h}$ stimulation at $1122 \mathrm{~nm}$ and $1 \mathrm{~W}$ was applied. (ii) Statistical comparison of release rate for control and stimulated (1122 $\mathrm{nm}$ for $1 \mathrm{~h}$ ) Lip, CLC and TX-100 samples in hydrogel. B. (i) The release rate for the control, stimulated and TX-100 CLC in hydrogel with different stimulation times is demonstrated. (ii) Statistical comparison of release rate for the stimulated CLCs in hydrogels of different stimulation durations is shown $(n=3)$. 


\section{Cytotoxicity of CLC gels in vitro}

One of the concerns with photothermally induced drug delivery systems is that they can cause side effects and toxicity to the tissue if the power intensity or temperature increase is too high. Moreover, SWCNTs have a high binding capacity to biological molecules, and if leaching from the gel occurs, can interact with live cells. Macrophages would be the first line of defense in such a scenario. ${ }^{56}$ Therefore, RAW 264.7 macrophages were selected as the cell line to examine potential adverse effects from the stimulated system. To assess toxicity effects of the gel itself and gel with $1 \mathrm{~h}$ NIR stimulation, Annexin V/ Propidium lodide apoptosis assay was used. Two-dimensional scatter plots were created to display the results of these assays (Figure 7). In these graphs, viable cells are shown at the bottom-left quadrant. The top-right quadrant shows necrotic cells, bottom-right quadrant shows apoptotic cells and top-left quadrant shows debris and cell junk. As there is not a significant difference between the necrotic and apoptotic cells for the different conditions, it can be concluded that the gels and NIR stimulation have minimal toxicity effects on macrophages in vitro. To assess the cytotoxicity of this system further, other cell lines in vitro and in vivo animal models should be used. 
A

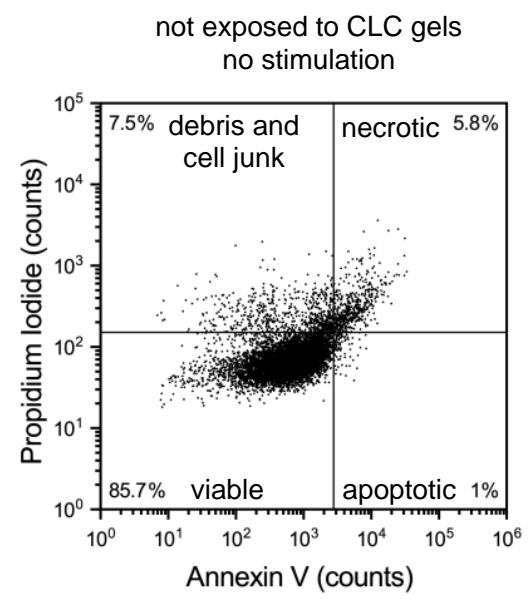

B

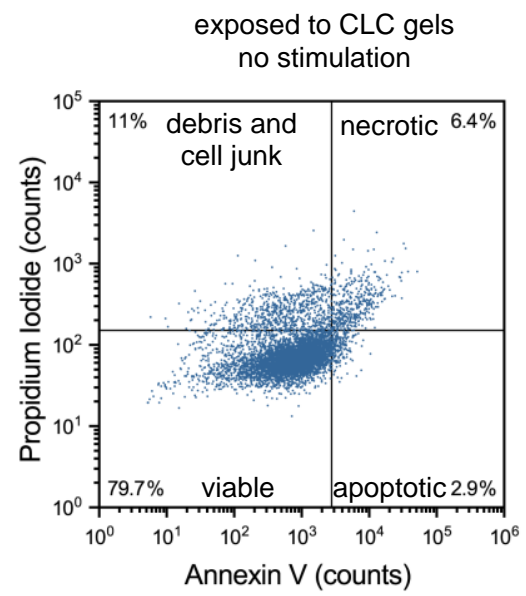

C

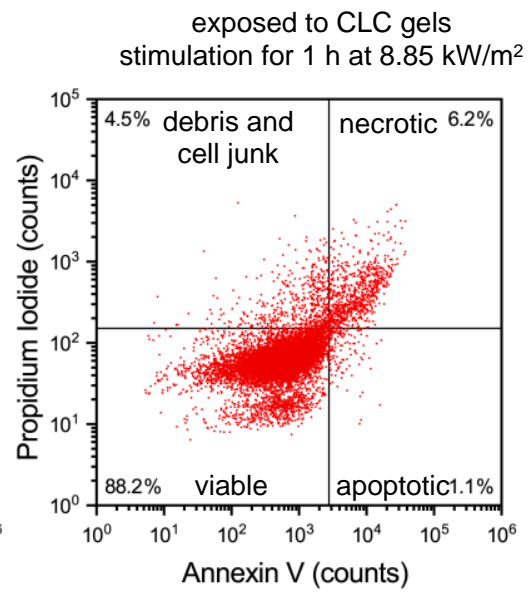

Figure 7. Cytotoxicity assays of macrophages exposed to CLC gels with or without NIR stimulation. A. Two-dimensional scatter of control cells not exposed to CLC gels or stimulation. B. Cells exposed to CLC gels with no stimulation. C. Cells exposed to CLC gels and stimulated with $1122 \mathrm{~nm}$ laser at $8.85 \mathrm{~kW} / \mathrm{m}^{2}$ for $1 \mathrm{~h}$.

\section{Conclusion}

In this study, we developed SWCNT-liposome complexes (CLC) for controlled triggered release. It was shown that the CLC structure is defined by the SWCNT/lipid ratio and an optimal ratio was selected for triggered release. Then, CLCs were integrated within a 3D hydrogel and it was shown that a model drug (FITC-Dex) can be retained for several days. Furthermore, an NIR laser was used to stimulate release of the model drug from the CLCs in the hydrogel scaffold. It was shown that stimulation time can be modified to modify the amount of drug release. To understand the cytotoxicity effects of CLC and NIR stimulation, Annexin V/ Propidium lodide apoptosis assay was used on RAW 264.7 macrophages and minimal toxicity was noticed in vitro. Further studies need to be conducted to investigate the application of this drug delivery system for delivering 
specific cancer chemotherapeutics at delayed time points and in vivo application of this drug delivery system.

\section{Acknowledgment}

This work was supported in part by the National Science Foundation Established Program to Stimulate Competitive Research (EPSCoR) under award OIA-1655221. This work is also supported by NSF award \#1603433. We would like to acknowledge the EPSCoR grant for supporting RIN2 and the Witec. We would like to acknowledge genomic and sequencing center at URI for allowing use of confocal microscopy. We would like to acknowledge Irene Andreu at RI Consortium for Nanoscience and Nanotechnology for conducting SEM imaging, Cryo-TEM imaging and helping with the confocal Raman microscopy.

\section{Supporting Information}

S1. Absorbance spectra of DNA functionalized SWCNT

S2. 3D z-stack of fluorescence confocal images of CLC gels at day 2 S3. Fluorescence emission spectra of $1 \mathrm{mg} / \mathrm{mL}$ FITC-Dex in presence of different SWCNT concentrations

S4. Images and swelling ratio of CLC gels before and after NIR laser stimulation S5. Colocalization analysis of Cy5 (attached to DNA strand on SWCNT) and FITCDex (encapsulated in liposome core)

S6. Representative Raman spectra at a random layer and average Raman spectra of all layers

S7. Analysis of slopes of heating and cooling cycles of pulsed NIR stimulation 


\section{References}

1. Siegel, R. L.; Miller, K. D.; Jemal, A., Cancer statistics, 2020. CA: A Cancer Journal for Clinicians 2020, 70 (1), 7-30.

2. Cao, D.; Zhang, X.; Akabar, M.; Luo, Y.; Wu, H.; Ke, X.; Ci, T., Liposomal doxorubicin loaded PLGA-PEG-PLGA based thermogel for sustained local drug delivery for the treatment of breast cancer. Artificial cells, nanomedicine, and biotechnology 2019, 47 (1), 181-191.

3. Krukiewicz, K.; Zak, J. K., Biomaterial-based regional chemotherapy: Local anticancer drug delivery to enhance chemotherapy and minimize its side-effects. Materials Science and Engineering: C 2016, 62, 927-942.

4. Chew, S. A.; Danti, S., Biomaterial-Based Implantable Devices for Cancer Therapy. Advanced healthcare materials 2017, 6 (2), 1600766.

5. De Souza, R.; Zahedi, P.; Allen, C. J.; Piquette-Miller, M., Polymeric drug delivery systems for localized cancer chemotherapy. Drug delivery 2010, 17 (6), 365-375.

6. Tiwari, A. P.; Hwang, T. I.; Oh, J.-M.; Maharjan, B.; Chun, S.; Kim, B. S.; Joshi, M. K.; Park, C. H.; Kim, C. S., pH/NIR-responsive polypyrrole-functionalized fibrous localized drugdelivery platform for synergistic cancer therapy. ACS applied materials \& interfaces 2018, 10 (24), 20256-20270.

7. Wolinsky, J. B.; Colson, Y. L.; Grinstaff, M. W., Local drug delivery strategies for cancer treatment: gels, nanoparticles, polymeric films, rods, and wafers. Journal of controlled release 2012, 159 (1), 14-26.

8. $\quad$ Alvarez, M. M.; Aizenberg, J.; Analoui, M.; Andrews, A. M.; Bisker, G.; Boyden, E. S.; Kamm, R. D.; Karp, J. M.; Mooney, D. J.; Oklu, R., Emerging trends in micro-and nanoscale technologies in medicine: From basic discoveries to translation. ACS Publications: 2017.

9. Emi, T. T.; Barnes, T.; Orton, E.; Reisch, A.; Tolouei, A. E.; Madani, S. Z. M.; Kennedy, S. M., Pulsatile Chemotherapeutic Delivery Profiles Using Magnetically Responsive Hydrogels. ACS biomaterials science \& engineering 2018, 4 (7), 2412-2423.

10. Madani, S. Z. M.; Reisch, A.; Roxbury, D.; Kennedy, S. M., A Magnetically Responsive Hydrogel System for Controlling the Timing of Bone Progenitor Recruitment and Differentiation Factor Deliveries. ACS Biomaterials Science \& Engineering 2020, 6 (3), 1522-1534.

11. Li, J.; Mooney, D. J., Designing hydrogels for controlled drug delivery. Nature Reviews Materials 2016, 1 (12), 1-17.

12. Khang, M. K.; Zhou, J.; Huang, Y.; Hakamivala, A.; Tang, L., Preparation of a novel injectable in situ-gelling nanoparticle with applications in controlled protein release and cancer cell entrapment. RSC advances 2018, 8 (60), 34625-34633.

13. Anirudhan, T.; Christa, J., Temperature and $\mathrm{pH}$ sensitive multi-functional magnetic nanocomposite for the controlled delivery of 5-fluorouracil, an anticancer drug. Journal of Drug Delivery Science and Technology 2020, 55, 101476.

14. Delcassian, D.; Patel, A. K., Nanotechnology and drug delivery. In Bioengineering Innovative Solutions for Cancer, Elsevier: 2020; pp 197-219.

15. Cheng, W.; Gu, L.; Ren, W.; Liu, Y., Stimuli-responsive polymers for anti-cancer drug delivery. Materials Science and Engineering: C 2014, 45, 600-608. 
16. Oshiro-Júnior, J. A.; Rodero, C.; Hanck-Silva, G.; Sato, M. R.; Alves, R. C.; Eloy, J. O.; Chorilli, M., Stimuli-responsive Drug Delivery Nanocarriers in the Treatment of Breast Cancer. Current medicinal chemistry 2020, 27 (15), 2494-2513.

17. Yang, H.; Khan, A. R.; Liu, M.; Fu, M.; Ji, J.; Chi, L.; Zhai, G., Stimuli-responsive polymeric micelles for the delivery of paclitaxel. Journal of Drug Delivery Science and Technology 2020, 101523.

18. Yang, K.; Feng, L.; Liu, Z., Stimuli responsive drug delivery systems based on nanographene for cancer therapy. Advanced drug delivery reviews 2016, 105, 228-241.

19. Cezar, C. A.; Kennedy, S. M.; Mehta, M.; Weaver, J. C.; Gu, L.; Vandenburgh, H.; Mooney, D. J., Biphasic ferrogels for triggered drug and cell delivery. Advanced healthcare materials 2014, 3 (11), 1869-1876.

20. Kennedy, S.; Hu, J.; Kearney, C.; Skaat, H.; Gu, L.; Gentili, M.; Vandenburgh, H.; Mooney, D., Sequential release of nanoparticle payloads from ultrasonically burstable capsules. Biomaterials 2016, 75, 91-101.

21. Kennedy, S.; Roco, C.; Déléris, A.; Spoerri, P.; Cezar, C.; Weaver, J.; Vandenburgh, H.; Mooney, D., Improved magnetic regulation of delivery profiles from ferrogels. Biomaterials 2018, 161, 179-189.

22. Moosavian, S. A.; Bianconi, V.; Pirro, M.; Sahebkar, A. In Challenges and pitfalls in the development of liposomal delivery systems for cancer therapy, Seminars in cancer biology, Elsevier: 2019.

23. Chen, Y.; Bose, A.; Bothun, G. D., Controlled release from bilayer-decorated magnetoliposomes via electromagnetic heating. ACS nano 2010, 4 (6), 3215-3221.

24. Preiss, M. R.; Bothun, G. D., Stimuli-responsive liposome-nanoparticle assemblies. Expert opinion on drug delivery 2011, 8 (8), 1025-1040.

25. Beltrán-Gracia, E.; López-Camacho, A.; Higuera-Ciapara, I.; Velázquez-Fernández, J. B.; Vallejo-Cardona, A. A., Nanomedicine review: clinical developments in liposomal applications. Cancer Nanotechnology 2019, 10 (1), 11.

26. Thirumaleshwar, S.; K Kulkarni, P.; V Gowda, D., Liposomal hydrogels: a novel drug delivery system for wound dressing. Current drug therapy 2012, 7 (3), 212-218.

27. Sirousazar, M.; Taleblou, N.; Roufegari-Nejad, E., Hydrogel and nanocomposite hydrogel drug-delivery systems for treatment of cancers. In Materials for Biomedical Engineering, Elsevier: 2019; pp 293-329.

28. Hong, G.; Diao, S.; Antaris, A. L.; Dai, H., Carbon nanomaterials for biological imaging and nanomedicinal therapy. Chemical reviews 2015, 115 (19), 10816-10906.

29. Zheng, M.; Jagota, A.; Strano, M. S.; Santos, A. P.; Barone, P.; Chou, S. G.; Diner, B. A.; Dresselhaus, M. S.; Mclean, R. S.; Onoa, G. B., Structure-based carbon nanotube sorting by sequence-dependent DNA assembly. Science 2003, 302 (5650), 1545-1548.

30. Liang, C.; Diao, S.; Wang, C.; Gong, H.; Liu, T.; Hong, G.; Shi, X.; Dai, H.; Liu, Z., Tumor metastasis inhibition by imaging-guided photothermal therapy with single-walled carbon nanotubes. Advanced materials 2014, 26 (32), 5646-5652.

31. Zhou, F.; Wu, S.; Wu, B.; Chen, W. R.; Xing, D., Mitochondria-targeting single-walled carbon nanotubes for cancer photothermal therapy. Small 2011, 7 (19), 2727-2735.

32. Beyene, A. G.; Delevich, K.; Del Bonis-O'Donnell, J. T.; Piekarski, D. J.; Lin, W. C.; Thomas, A. W.; Yang, S. J.; Kosillo, P.; Yang, D.; Prounis, G. S., Imaging striatal dopamine 
release using a nongenetically encoded near infrared fluorescent catecholamine nanosensor. Science advances 2019, 5 (7), eaaw3108.

33. Gravely, M.; Safaee, M. M.; Roxbury, D., Biomolecular Functionalization of a Nanomaterial To Control Stability and Retention within Live Cells. Nano letters 2019, 19 (9), 6203-6212.

34. Budhathoki-Uprety, J.; Shah, J.; Korsen, J. A.; Wayne, A. E.; Galassi, T. V.; Cohen, J. R.; Harvey, J. D.; Jena, P. V.; Ramanathan, L. V.; Jaimes, E. A., Synthetic molecular recognition nanosensor paint for microalbuminuria. Nature communications 2019, 10 (1), 1-9.

35. Harvey, J. D.; Baker, H. A.; Ortiz, M. V.; Kentsis, A.; Heller, D. A., HIV detection via a carbon nanotube RNA sensor. ACS sensors 2019, 4 (5), 1236-1244.

36. Saleemi, M.; Kong, Y.; Yong, P.; Wong, E., An overview of recent development in therapeutic drug carrier system using carbon nanotubes. Journal of Drug Delivery Science and Technology 2020, 101855.

37. Zhang, W.; Zhang, Z.; Zhang, Y., The application of carbon nanotubes in target drug delivery systems for cancer therapies. Nanoscale research letters 2011, 6 (1), 555.

38. Miyako, E.; Kono, K.; Yuba, E.; Hosokawa, C.; Nagai, H.; Hagihara, Y., Carbon nanotube-liposome supramolecular nanotrains for intelligent molecular-transport systems. Nature communications 2012, 3 (1), 1-9.

39. Karchemski, F.; Zucker, D.; Barenholz, Y.; Regev, O., Carbon nanotubes-liposomes conjugate as a platform for drug delivery into cells. Journal of Controlled Release 2012, 160 (2), 339-345.

40. Jena, P. V.; Safaee, M. M.; Heller, D. A.; Roxbury, D., DNA-carbon nanotube complexation affinity and photoluminescence modulation are independent. ACS applied materials \& interfaces 2017, 9 (25), 21397-21405.

41. Safaee, M. M.; Gravely, M.; Lamothe, A.; McSweeney, M.; Roxbury, D., enhancing the thermal Stability of carbon nanomaterials with DnA. Scientific reports 2019, 9 (1), 1-11.

42. Safaee, M. M.; Gravely, M.; Rocchio, C.; Simmeth, M.; Roxbury, D., DNA sequence mediates apparent length distribution in single-walled carbon nanotubes. ACS applied materials \& interfaces 2018, 11 (2), 2225-2233.

43. Godin, A. G.; Varela, J. A.; Gao, Z.; Danné, N.; Dupuis, J. P.; Lounis, B.; Groc, L.; Cognet, L., Single-nanotube tracking reveals the nanoscale organization of the extracellular space in the live brain. Nature nanotechnology 2017, 12 (3), 238-243.

44. Cirillo, G.; Hampel, S.; Spizzirri, U. G.; Parisi, O. I.; Picci, N.; lemma, F., Carbon Nanotubes Hybrid Hydrogels in Drug Delivery: A Perspective Review. BioMed Research International 2014, 2014, 825017.

45. Galassi, T. V.; Jena, P. V.; Shah, J.; Ao, G.; Molitor, E.; Bram, Y.; Frankel, A.; Park, J.; Jessurun, J.; Ory, D. S., An optical nanoreporter of endolysosomal lipid accumulation reveals enduring effects of diet on hepatic macrophages in vivo. Science translational medicine 2018, 10 (461), eaar2680.

46. Harvey, J. D.; Jena, P. V.; Baker, H. A.; Zerze, G. H.; Williams, R. M.; Galassi, T. V.; Roxbury, D.; Mittal, J.; Heller, D. A., A carbon nanotube reporter of microRNA hybridization events in vivo. Nature biomedical engineering 2017, 1 (4), 1-11. 
47. Roxbury, D.; Jena, P. V.; Williams, R. M.; Enyedi, B.; Niethammer, P.; Marcet, S.; Verhaegen, M.; Blais-Ouellette, S.; Heller, D. A., Hyperspectral microscopy of near-infrared fluorescence enables 17 -chirality carbon nanotube imaging. Scientific reports 2015, 5 (1), 1-6. 48. Zhang, H., Thin-film hydration followed by extrusion method for liposome preparation. In Liposomes, Springer: 2017; pp 17-22.

49. Norouzi, M.; Nazari, B.; Miller, D. W., Injectable hydrogel-based drug delivery systems for local cancer therapy. Drug discovery today 2016, 21 (11), 1835-1849.

50. Coleman, J. N.; Khan, U.; Blau, W. J.; Gun'ko, Y. K., Small but strong: a review of the mechanical properties of carbon nanotube-polymer composites. Carbon 2006, 44 (9), 16241652.

51. Spitalsky, Z.; Tasis, D.; Papagelis, K.; Galiotis, C., Carbon nanotube-polymer composites: chemistry, processing, mechanical and electrical properties. Progress in polymer science 2010, 35 (3), 357-401.

52. Jin, S.; Wijesekara, P.; Boyer, P. D.; Dahl, K. N.; Islam, M. F., Length-dependent intracellular bundling of single-walled carbon nanotubes influences retention. Journal of Materials Chemistry B 2017, 5 (32), 6657-6665.

53. Holt, B. D.; Dahl, K. N.; Islam, M. F., Quantification of uptake and localization of bovine serum albumin-stabilized single-wall carbon nanotubes in different human cell types. Small 2011, 7 (16), 2348-2355.

54. Yang, F.; Wang, M.; Zhang, D.; Yang, J.; Zheng, M.; Li, Y., Chirality Pure Carbon Nanotubes: Growth, Sorting, and Characterization. Chemical Reviews 2020.

55. Zhang, Y.; Zhan, X.; Xiong, J.; Peng, S.; Huang, W.; Joshi, R.; Cai, Y.; Liu, Y.; Li, R.; Yuan, K., Temperature-dependent cell death patterns induced by functionalized gold nanoparticle photothermal therapy in melanoma cells. Scientific reports 2018, 8 (1), 1-9. 56. Huber, L. C.; Jüngel, A.; Distler, J. H.; Moritz, F.; Gay, R. E.; Michel, B. A.; Pisetsky, D. S.; Gay, S.; Distler, O., The role of membrane lipids in the induction of macrophage apoptosis by microparticles. Apoptosis 2007, 12 (2), 363-374. 


\section{Graphic for manuscript}

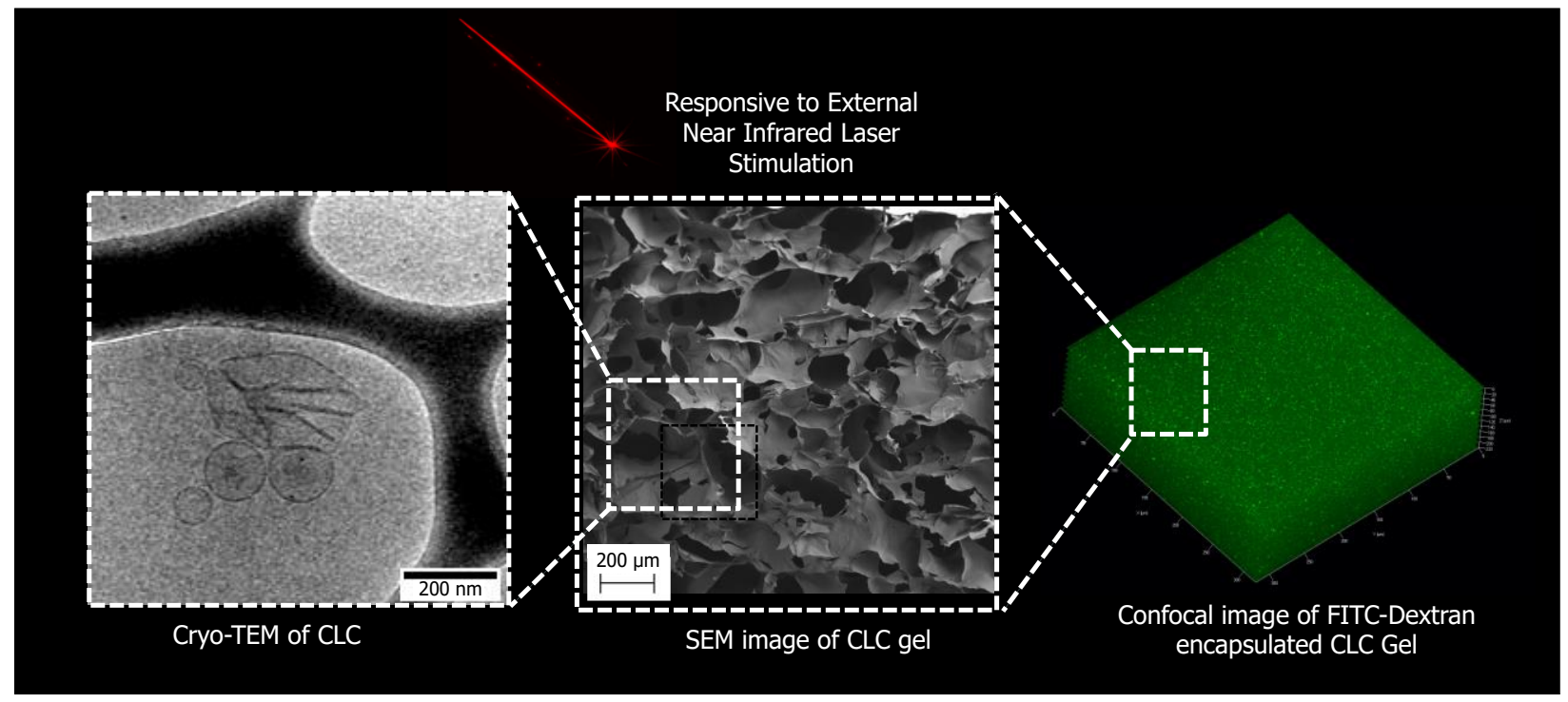

